\title{
DESIGN OF A SIMPLE VENDING MACHINE USING RADIO FREQUENCY IDENTIFICATION (RF-ID)
}

\begin{tabular}{|l|l|}
\hline Sunil Kumar & Richa Pandey \\
Dept. of Electrical \& Electronics Engineering & Dept. of Mechanical Engineering \\
Birla Institute of Technology Mesra & Birla Institute of Technology Mesra \\
Ranchi, India & Ranchi, India \\
skumar2908@gmail.com & richarp@ rediffmail.com \\
\hline
\end{tabular}

\begin{abstract}
The concept and challenge of vending machine in India is getting higher as technology has advanced. The proposed work relates to the design of a real time vending machine. This can serve small enterprises with less initial cost and also for common products. The design is formulated by keeping the Radio frequency identification (RF-id) code as the base which is being generated for different regular customers. This shall help both ways in simplify the transaction and complexity. The two or three products which are being identified are programmed as per their cost which serve for better dealing. The three identified inputs are (1) Quality (2) Quantity (3) Costing. This machine is helpful to purchase day to day needs, in places like Hostel, Hospital, canteen etc.
\end{abstract}

Keywords-Radio Frequency Identification Arduino UNO R3,Spline, Auger, Vending Machine

(RFID),

\section{INTRODUCTION}

Vending machines providing soft drink [4] or beverages [5] are common in market but in India it is very rare to get machine which can provide other day to day products. Our main motive is to design a low cost and effective vending machine, which can provide other small products. Vending machine is a machine which dispenses an item such as snacks, medicines, food items, beverages etc. to customers automatically on payment into slots of the machine. The principle is so simple: the customers pay to the machine, and the machine will give the user's selected goods. The credit of vending machine goes to Hero of Alexandria, a first-century engineer and mathematician. Typically two types of payment modes are available for payment purposes: Credit/Debit Cards or Cash [1].

Vending machine has become a widely increasing channel for sales gradually, especially for Food and Beverages companies. They offer various benefits such as portability in terms of set up, low cost driven and offer wide reach due to less space constraints. Vending machines are now designed in such a way that their status can be known from far space. Most of the vending machines are based on CMOS, SED and Microcontroller technologies [1].

This paper presents a novel design of simple vending machine using Radio Frequency Identification (RFID).

So, in simple way we can say that vending machine is a machine that used to sell goods without human monitoring. An automatic beverages vending machine using Finite State Machine is proposed [1]. A distributed and cascade lossy source coding with a side information vending machine using control decoder technique is used [2]. In China vending machine operated by GPRS were also developed. Where people can order items by using their phone number and also they can pay bill by using GPRS [3].

\section{METHODOLOGY}

In this article a vending machine is designed and operated by using RF-id in spite of using money. The internal circuit consists of stepper motor, LCD display, Arduino Uno R3 microcontroller, Push button and IR sensor.

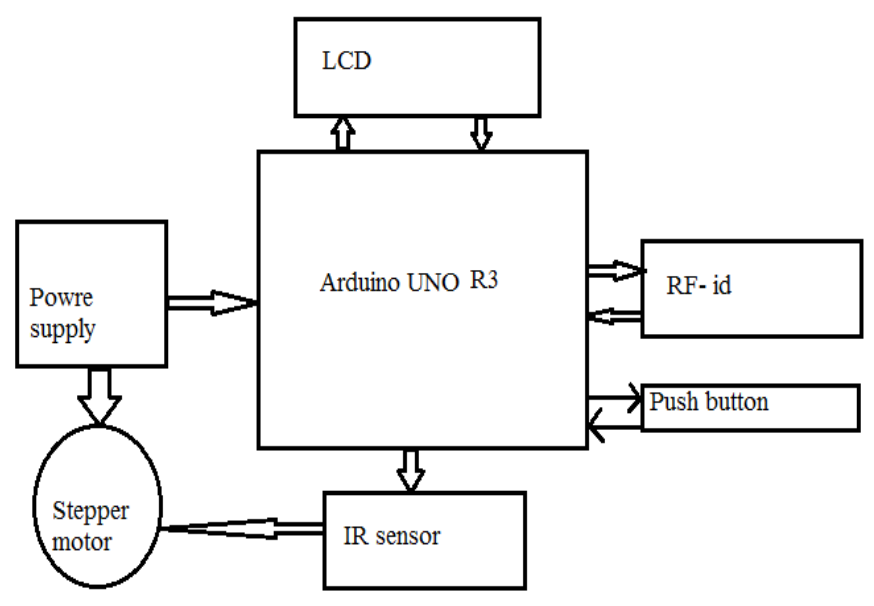

Fig. 1. Schematic diagram of the vending machine

In the above figure the layout of vending machine is shown. As shown in figure when the system got power supply the microcontroller will go to on stage and it will run the loaded program. According to the program "select item" will display on the LCD screen. Then customer will select the required product by pushing the respective pushbutton. Then the microcontroller will ask to insert RFid for further processing. After touching the RF-id, the LCD will show command to choose the quantity for the opted product. When the customer mention the required quantity the motor will turn as programmed in the microcontroller and the items will fall down at the bottom of vending machine. 
ELK

\section{Asia Pacific Journals}

\section{A. Stepper Motor}

A stepper motor is a brushless, synchronous electric motor that can divide a full rotation into a large no. of steps. The motor's position can be controlled precisely without any feedback mechanism. A Stepper motor works on the principle of electromagnetism. There is a soft iron/magnetic rotor shaft surrounded by the electromagnetic stators. The stator and rotor have poles which are teethed. When the stator are energized the rotor moves to align itself along with the stator.

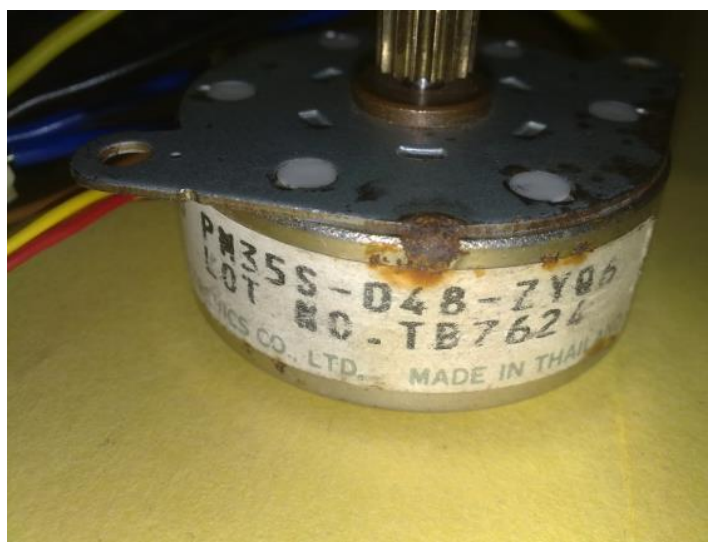

Fig. 2. Steeper motor

TABLE I. SPECIFICATION OF STEPPER MOTOR

\begin{tabular}{|c|c|}
\hline Motor Type & PM Stepper \\
\hline Step Angle & 7.50 degree \\
\hline Step per Rotation & 48 \\
\hline Frame Size & $35 \mathrm{~mm}$ \\
\hline Max. Holding Torque & $20 \times 10^{-3} \mathrm{Nm}$ \\
\hline Drive circuits & Unipolar \\
\hline Drive Voltage & $24 \mathrm{~V}$ \\
\hline Coil resistance per phase & $50 \mathrm{ohm}$ \\
\hline Insulation Resistance & $100 \mathrm{ohm}$ \\
\hline
\end{tabular}

\section{B. IR Sensor}

IR sensor consist of transmitter and receiver LED to detecting the object according to adjustment of sensitivity. Transmitted light received by receiver after reflection through an object. Its working is based on Reflected light incident on reverse biased IR sensor. When photons are incident on reverse biased junction of this diode, electron hole pairs are generated. As a result reverse leakage current were found. This IR sensor is used for detecting the motor rotation, according to selection of an item and also the amount of an item.

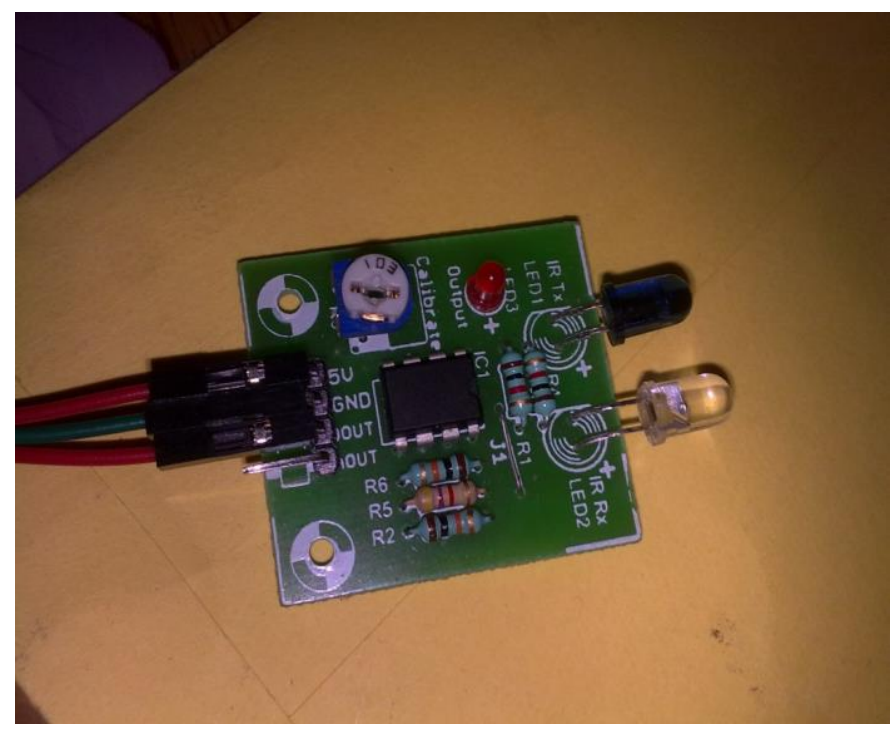

Fig. 3. IR Sensor

\section{Arduino UNO R3 microcontroller}

The Arduino UNO R3 [7] is a microcontroller board based on the ATmega328. It has 14 digital input/output pins out of which, 6 analog inputs, 6 can be used as PWM outputs a $16 \mathrm{MHz}$ ceramic resonator, a USB connection, a reset button, a power jack, and an ICSP header. It contains everything needed to support the microcontroller; simply connect it to a computer with a USB cable or power it with an AC-to-DC adapter or battery to get started.

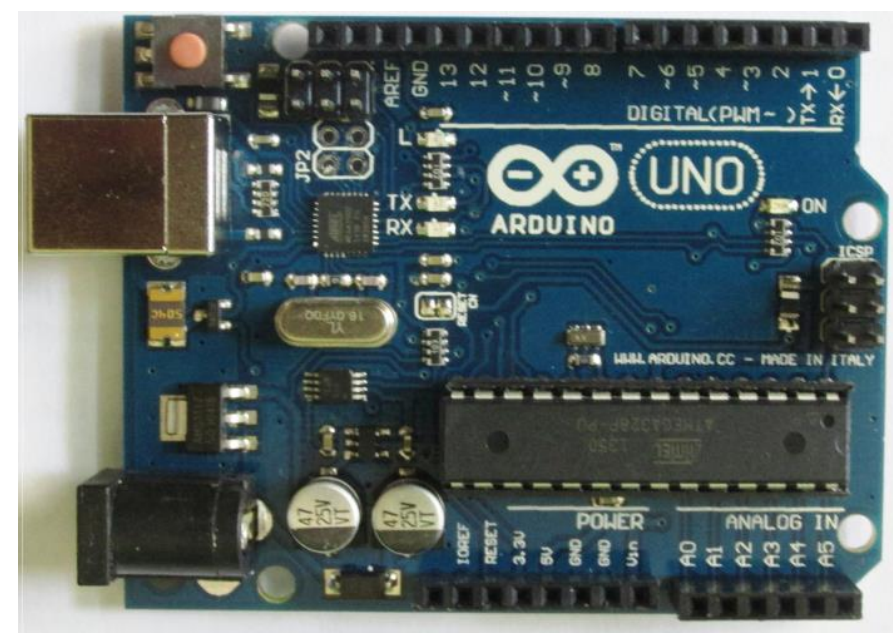

Fig. 4. Arduino UNO R3

D. LCD Display \& RF-id

A LCD Display is used to display the selection of item appear on the screen after pressing the push button and RFid [6] will be provided to selective customers only, so that they can operate the vending machine whatever they want. 
ELK

Asia Pacific Journals

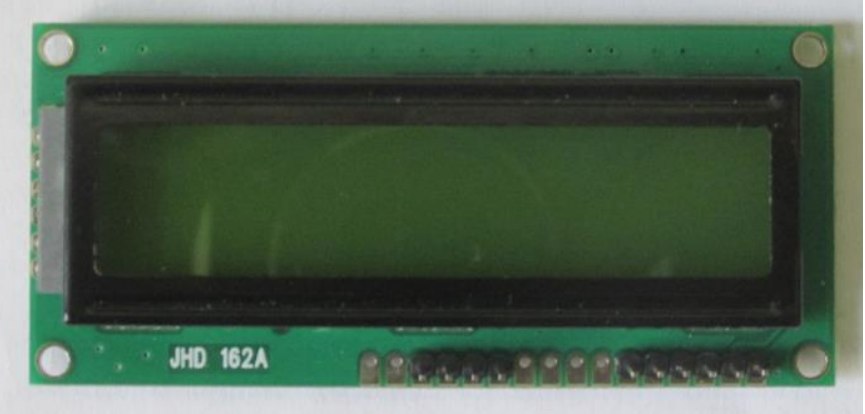

Fig. 5. LCD display

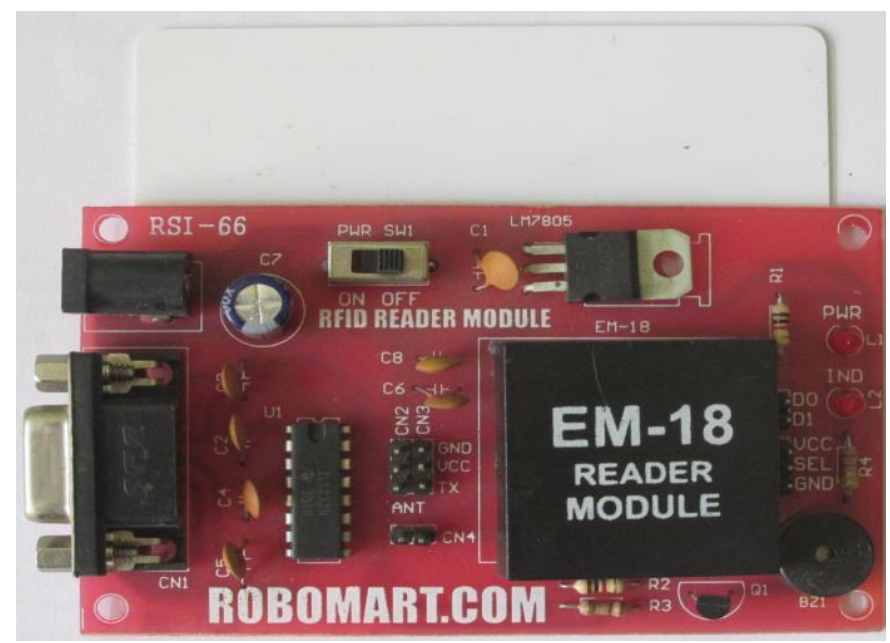

Fig. 6. RF-id

TABLE II. Product Types

\begin{tabular}{|c|c|c|}
\hline S.No & Products & Select Option \\
\hline 1 & Kurkure & Select 1 \\
\hline 2 & Candy & Select 2 \\
\hline
\end{tabular}

These tables shows that selection of two products which is available in the vending machine i.e. Kurkure and Candy in select1 and select 2 respectively as input provided by the customers through RF-id.

\section{PROPOSED ALGORITHM}

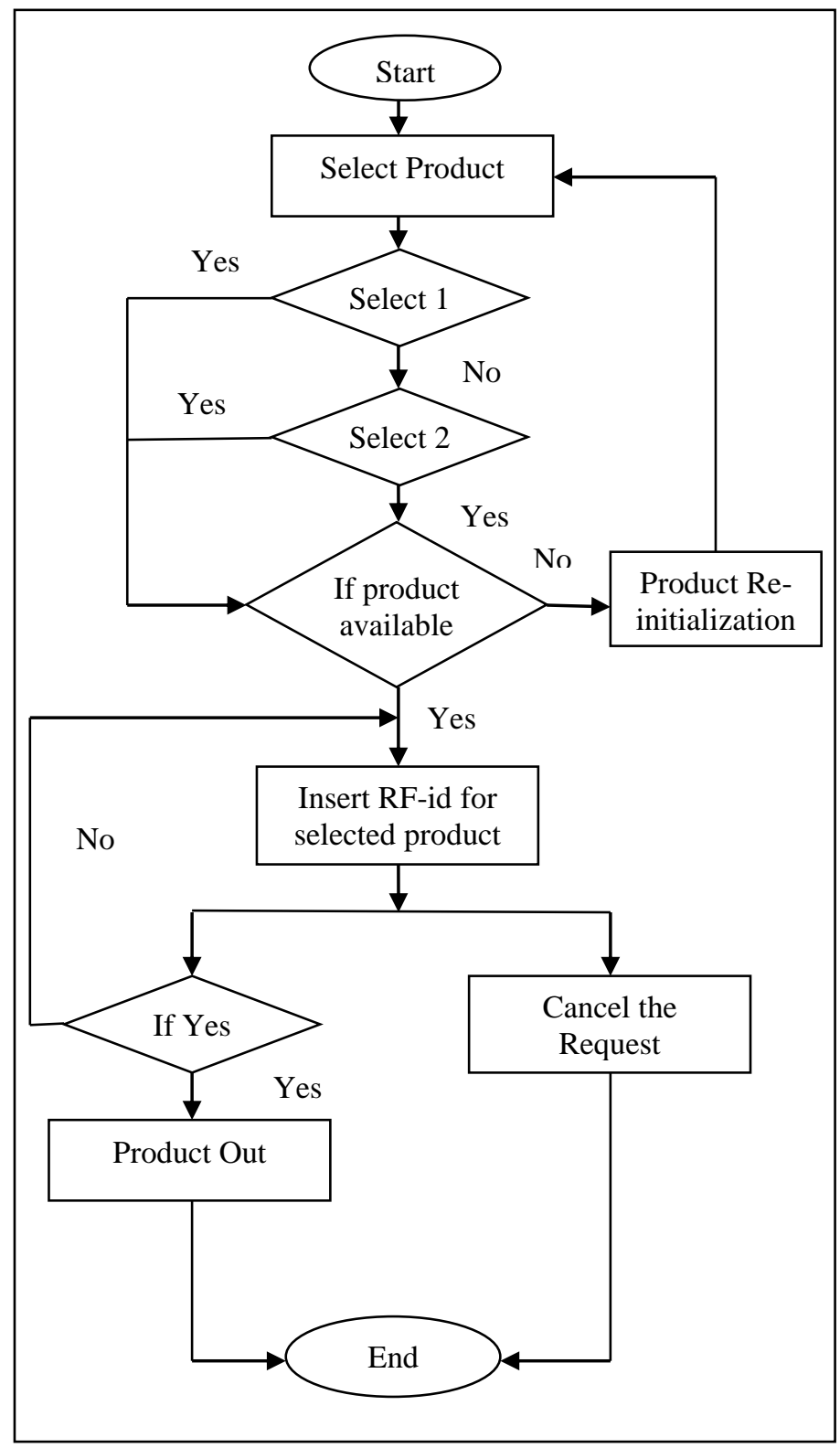

Fig.7. Flowchart for proposed Vending Machine

Our proposed algorithm works on various steps, first: in the initial step the operation starts with selecting the desired product, after selection of product it check its availability if it is available then the vending machine will wait for taking RF-id else if it is not available then again initialization of product takes place. If RF-id does not recognize with the database of the vending machine then it will automatically cancel the request of the customer, if RF-id matched with the database then product is obtained from the Vending Machine. 


\section{Asia Pacific Journals}

\section{RESULTS AND CONCLUSION}

This paper mainly focuses on the design of a low cost and effective vending machine, which can provide day to day goods. To implement the machine we interface software and hardware components and try to make it simpler as well as compact, so that it can be carry or place anywhere. At the same time the use of Arduino UNO microcontroller make the system more versatile.

\section{ACKNOWLEDMENT}

We are thankful to Robomart for providing RF-id, Arduino UNO R3 microcontroller, stepper motor in my project. We are also thankful to our guide Mrs. Richa Pandey for their valuable guidance. We are also gladful to Dr. M.K Mishra, Vice Chancellor, BIT Mesra and Prof. R.C. Jha, H.O.D EEE, BIT Mesra, for providing continuous inspiration and encouragement.

\section{REFERENCES}

[1] V.V.S vijay krishna et.al "Design and implementation of an automatic Beverages Vending Machine and its Performance Evaluation using Xilinx ISE and Cadence" IEEE $4^{\text {th }}$ ICCNT July 4-6 2013 .

[2] Behzad Ahmadi, Osvaldo Simeone "Distributed and cascade lossy source coding with a side information vending machine"IEEE transaction on information theory, vol. 59, No 10, october 2013 pp 6807-6819.

[3] Zhang Wen, Zhang Xin Long, "Design and implementation of automatic vending machine based on the short message payment", 2010 IEEE.

[4] Kwangsoo Kim, Dong Hwan Park, Hyochan Bang, "Smart coffee vending machine using sensor and actuator network". 2014 IEEE.

[5] Tao Xu, Yongen Chen, Yu Feng, "The design of intelligent multimedia automatic beverage machine coontrol system", International conference on measuring technology and mewchatronics automation, 2010.

[6] http://en.wikipedia.org/wiki/Radio-frequency_identification

[7] http://arduino.cc/en/main/arduinoBoardUno 